\title{
Interpreting Bare Nouns: Type-Shifting vs. Silent Heads*
}

\author{
Yu Izumi \\ University of Maryland
}

\begin{abstract}
Bare noun phrases in article-less languages such as Japanese have a variety of interpretations. There are two competing approaches to the semantics of bare noun phrases: one is to appeal to type-shifting to derive various interpretations, and the other is to introduce more structure, i.e., silent determiners. I present an argument against the latter silent-head approach based on the behaviors of phonologically null arguments in Japanese. The silent-head approach has difficulties in explaining the semantics of null arguments, whatever syntactic analysis of null arguments turns out to be correct. The type-shifting approach to bare noun phrases, by contrast, easily accounts for the semantics of null arguments.
\end{abstract}

Keywords: bare noun; type-shifting; silent determiner; null argument; Japanese

\section{Introduction: two approaches to bare noun phrases}

Seemingly determiner-less, 'bare' noun phrases (BNPs) in article-less languages such as Chinese and Japanese have a variety of uses, where the attested meanings don't map onto overt syntactic elements. As shown in the Japanese examples (1-4), sentences that contain one and the same noun (e.g., inu 'dog') yield four different sorts of interpretations. The natural reading of (1) is concerned with the whole canine species, not merely with some or other dog, whereas (2) reports an event involving some or other dog, not the entire species. (3) attributes a property to the vast majority of dogs, whereas (4) is about a particular dog and nothing else.

(1) Inu-ga zetumetusita.

dog-NOM extinct.became

'Dogs went extinct.' (Kind-referential)

(2) Inu-ga hoeta.

dog-NOM barked

'A dog/dogs barked.' (Existential)

* I would like to thank Alexander Williams, Jun Abe, Kenshi Funakoshi, Valentine Hacquard, Paul Pietroski, and the editors of the Proceedings for their useful feedback. I would also like to thank the audience of SALT XXI at Rutgers and of LSALAA 2011, the Workshop on Languages With and Without Articles, in Paris for helpful discussions and comments.

(C)2011 Yu Izumi 
(3) Inu-ga hoeru no-wa atarimae-da. dog-NOM bark COMP-TOP obvious-be

'It's obvious that dogs bark.' (Characterizing)

Sakki hoeteita inu-ga bar-ni haittekita. earlier barking.was dog-NOM bar-to entered.

'The dog that was barking earlier entered the bar.' (Referential or Anaphoric)

In general, there are two approaches to this interpretive variability of BNPs. One is to posit some type-shifting rules that derive different interpretations from one and the same lexical meaning (Partee 1986; Chierchia 1998; Dayal 2004); and the other is to posit some unpronounced syntactic heads that encode interpretive features (Cheng \& Sybesma 1999; Watanabe 2006). The former type-shifting approach takes the surface form of a BNP seriously and introduces complexity at the level of semantics. The latter silent-head approach objects to the idea that a BNP is really bare or determiner-less. It preserves a straightforward syntax-semantics mapping by introducing silent lexical items, not mere semantic rules.

For example, on the one hand, the type-shifting approach might explain the referential or anaphoric use of a BNP in (4) by means of the type-shifting operation ' $l$ ', which is basically what the English definite article the encodes as its lexical meaning. The $\imath$ operation applies to the meaning of the noun inu ('dog') to yield a value of type $\langle e\rangle$. On the other hand, the silent-head approach would understand the same phenomenon in terms of a complex structure. Nothing seems to prevent us from introducing a silent lexical item that encodes the $l$ operation. On the silent-head approach, we can think of a structure like the following:

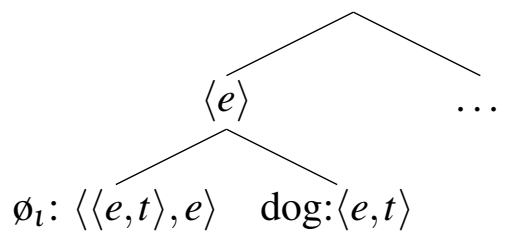

where the BNP $\operatorname{dog}$ is a complex phrase whose overall content, i.e., the value of type $\langle e\rangle$, is partially determined by the silent determiner $\emptyset_{l}$.

We can never adjudicate between the two options if we just look at the semantics of BNPs. Both approaches can produce the same semantic results with respect to BNPs because any type-shifting rule can be treated as an interpretive feature of a silent determiner, and vice versa. Perhaps, in the near future, we will be able to test the two approaches on the basis of independent criteria, such as processing time and measurement of brain activity (Pylkkänen 2008). I wish to show, however, that we are already able to distinguish the two approaches without using such psycholinguistic criteria if we consider a broader context. 
Interpreting Bare Nouns

In what follows I will offer an independent argument against the silent-head approach based on the behaviors of Japanese unpronounced arguments that take BNPs as their antecedents. The silent-head approach has difficulties in explaining the semantics of phonologically null arguments. I will also argue that the type-shifting approach does not face the same problem.

\section{Interpretive independence of null argument anaphora}

I want to first present an interpretive characteristic of unpronounced arguments in Japanese that is crucial for the argument against silent determiners that I will offer in the next section.

Japanese is a 'radical' pro-drop language that allows any thematic argument to be left unpronounced without explicit marking. I will call an instance of implicit argument that seems to have a linguistic antecedent 'null argument anaphora' (NAA).

The interpretation of NAA does not have to be equivalent to that of its antecedent as shown in (6-8).

(6) Americajin-ga cola-o hatumeisi, Doitujin-ga [ø] syohisita.

American-NOM cola-ACC invented.and, German-NOM [ $\varnothing]$ consumed

'An American invented cola; Germans consumed it.'

IBM-ga smartphone-o hatumeisi, kono-hito-ga saisyoni [ $\varnothing]$

IBM-NOM smartphone-ACC invented.and, this-person-NOM first [ø]

konyusita.

purchased

'IBM invented the smartphone and this guy purchased one first.'

(8) Aru Portugaljinno funanori-ga dodo-o saisyoni tabe, Olandajin-ga

a.certain Portuguese sailor-NOM dodo-ACC first eat, Dutch-NOM

notini [ $\varnothing$ ] zetumetusa-seta.

later $[\varnothing]$ extinct.become-forced

'A Portuguese sailor ate a dodo first, and the Dutch people later exterminated them.'

The first clause is used to say something about cola, the kind. But the second clause is not. Plausibly this shows that the BNP cola in the first clause refers to a kind, while the NAA $\varnothing$ in the second clause has an existential interpretation, denoting some quantity of cola-Germans must have consumed only some amount of cola, not the whole kind. (7) is an analogous case where its NAA should also be existentially interpreted. (8) exhibits the opposite pattern. The antecedent BNP dodo in (8) invokes an existential quantification while the NAA refers to the entire species. I will refer to the observed semantic mismatch between BNPs and NAA as the 'interpretive 
independence of NAA'. On the basis of NAA's interpretive independence, I will present an argument against any semantic analysis of BNPs that posits a silent determiner.

\section{Argument against the silent-head approach}

The main line of reasoning in this section goes as follows. NAA is analyzed either as a kind of ellipsis or as a kind of pronoun. Either way, the silent-head approach to BNPs would have difficulties in explaining the interpretive independence of NAA observed above. Therefore, by reductio, the silent-head approach is problematic when we consider a broader context, even if it adequately captures the behaviors of BNPs.

It is controversial what the right syntactic analysis of NAA is. NAA might be an ellipsis phenomenon (Takahashi 2008). Alternatively NAA might amount to unpronounced pronouns (Hoji 1998). Perhaps Japanese null arguments consist of more than one type of phenomena, and both ellipsis and pronominal analyses are correct in different cases (Abe 2009). I do not have to decide, however, among the possible syntactic analyses of NAA because I will argue that the silent-head approach has limitations, whatever analysis of NAA turns out to be on the right track.

\subsection{Ellipsis analysis of null argument anaphora}

Let's first suppose that NAA in sentences like (6-8) are elliptical. Also suppose, for reductio, that BNPs include silent determiners that are responsible for their interpretations, i.e., that the silent-head approach is correct. For example, the BNP cola in (6) is analyzed as follows:

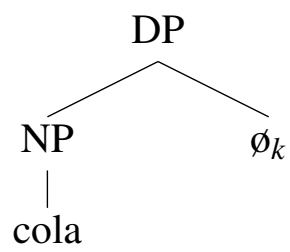

where $\emptyset_{k}$ is the silent determiner whose interpretive feature somehow contributes to the kind interpretation of the phrase.

If this is the right picture of BNPs, then the interpretive independence of NAA is best explained as an instance of NP-deletion: NAA $\varnothing$ is a maximal projection of a silent determiner whose constituent NP gets deleted or unpronounced. For example, NAA $\varnothing$ in (6) can be analyzed as follows: 
Interpreting Bare Nouns

(10)

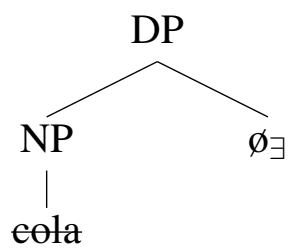

where $\emptyset_{\exists}$ is unpronounced and introduces an existential quantification. The overall structure (10) remains silent and has an existential interpretation whose content is related but not identical to its antecedent interpretation ('the kind cola'). The silent determiner in the antecedent BNP is irrelevant to the choice of determiner in (10). BNPs and NAA can have different interpretations because of the presence of silent determiners.

We can in fact find an analogous case of NP-deletion inside a quantificational phrase in English:

a. John bought [every [NP required textbook]], but Mary bought only [some/a few [NP required textboek ]].

b. John bought [two [NP books]], and Mary bought [four [NP books ]].

It might seem natural to assume that what can be done in English can also be done in Japanese.

Such an assumption is, however, unfounded. Japanese does not allow NPdeletion when a quantificational or demonstrative modifier is overtly present.

*Taro-wa [ikutukano/ichidaino kuruma] -o kai, Hanako-wa
Taro-TOP several/1.CL car -ACC bought.and, Hanako-TOP
[subeteno/sandaino kuruma] -(o) katta.
every/3.CL car -(ACC) bought.

'Taro bought several/one car(s), and Hanako bought every/three car(s)'

*Taro-wa [kono/korerano kuruma] -o kai, Hanako-wa
Taro-TOP this/these car -ACC bought.and, Hanako-TOP
[ano/arerano/ kuruma] -(o) katta.
that/those car -(ACC) bought.
'Taro bought this/these car(s), and Hanako bought that/those one(s)'

Both (12) and (13) would be perfectly grammatical were there no ellipsis. The impossibility of NP-deletion in (12) and (13) undermines the analysis of NAA represented by (10). Therefore, the silent-head approach has no simple explanation for the interpretive independence of NAA when we assume that NAA is elliptical.

One might wonder whether the impossibility of NP-deletion in (12) and (13) is due to their particular configuration, and whether NP-deletion is possible in some 
other context, which would be an overt counterpart of (10). Indeed Japanese allows NP-deletion in limited circumstances even when an NP is modified by a determinerlike expression. Now I turn to such cases to see if there is any evidence for the NP-deletion in (10).

NP-deletion in Japanese seems possible only when (i) an NP is modified by a possessive no-phrase or (ii) an NP has a floating quantifier (FQ). I will argue that both cases are not analogous to the structure (10) and cannot support the analysis of NAA under consideration.

Possessive no-phrases The following examples (14-17) suggest that NP-deletion is possible if a stranded no-phrase is relational in some sense, and paraphrasable by means of an of-phrase in English. The individual Hanako referred to by the no-phrase Hanako no in (14) is the possessor of an implicit object. That is, what is deleted is the attitude 'of Hanako'. Kyoto no hakai in (15) indicates the destruction 'of Kyoto'; and kinoo no ondo in (16) must be understood as the temperature 'of yersterday'. The nouns can be deleted in those three cases (14-16). By contrast, (17) is clearly ungrammatical, where the no-phrase ame no plays a role of an adjective and has no relational meaning, which cannot be understood as 'of rainy', whatever that would mean.

(14) [Taro no taido] -wa yoi ga, [Hanako no taide] -wa yokunai. Taro 's attitude -TOP good though, Hanako 's attitude -TOP good.not 'Though Taro's attitude is good, Hanako's isn't.' (Saito, Lin \& Murasugi 2008: 253)

(15) [Rome no hakai] -wa [Kyoto no hakai] -yorimo hisan datta. Rome 's destruction -TOP Kyoto 's destruction -than miserable was 'Rome's destruction was more miserable than Kyoto's.' (Saito et al. 2008: 253)

(16) [Kyoo no ondo] -wa [kinoo no ende] -yorimo takai today no temperature -TOP yesterday no temperature -than high

'Today's temperature is higher than yesterday's.' (Saito et al. 2008: 254)

(17) *[Hare no hi]-wa yoi ga, [ame no hi]-wa otikomu. clear no day-TOP good though, rain no day-TOP feel.depressed 'Sunny days are OK, but I feel depressed on rainy days.' (Saito et al. 2008: 253)

If the silent determiners required for the ellipsis analysis of NAA fall under the category of these relational no-phrases, then what they modify could be deleted, i.e., 
Interpreting Bare Nouns

the NP-deletion in (10) would be plausible. The silent determiners can hardly be considered relational, however. For example, the determiner $\emptyset_{\exists}$ in (10) cannot be paraphrased by any of-phrase. We cannot identify the other relatum for cola unlike for the deleted nouns in (14-16). Therefore, the instances of NP-deletion in (14-16) are irrelevant to the hypothesized NP-deletion required for the silent-head approach to explain the interpretive independence of NAA.

Floating quantifiers It is also possible in Japanese to delete an NP and leave a floating quantifier (FQ) behind. Japanese quantificational phrases, including numerals, need not be adjacent to the modified nouns as example (18) indicates, where a quantificational phrase may appear away from what it modifies. NP-deletion is possible in such circumstances like (18) and (21), whereas slightly different constructions, such as (19) and (20), exclude NP-deletion, where a quantificational phrase appears either prenominally or in between the noun and its case.

NP-CASE-(ADVERB)-QP

Boku-wa hon-o (campus-de) [i-satu] kai, Hanako-wa I-TOP book-ACC (campus-on) one-CL bought, Hanako-TOP

hen- $\quad$ (Amazon-de) [san-satu] katta.

book-ACC (Amazon-on) three-CL bought

'I bought one book (on campus), and Hanako bought three (on Amazon).'

(19) QP-no-NP-CASE

*Taro-wa iti-niti-ni [san-satu no hon]-o yomu ga, Hanako-wa Taro-TOP one-day-in three-CL no book-ACC read though, Hanako-TOP [go-satu no hon] -o yomu.

five-CL no book -ACC read

'Taro reads three books in a day, but Hanako reads five.' (Saito et al. 2008: 253)

(20) NP-QP-CASE

?Boku-wa [inu i-ppiki]-o turetekita ga, Hanako-wa [int I-TOP dog one-CL-ACC brought though, Hanako-TOP dog ni-hiki]-o turetekita. two-CL-ACC brought

'I brought one dog, but Hanako brought two.'

NP-CASE-(ADVERB)-QP 
Boku-wa [inu i-ppiki]-o turetekita ga, Hanako-wa int-o I-TOP dog one-CL-ACC brought though, Hanako-TOP dog-ACC (gakko-ni) [ni-hiki] turetekita. (school-to) two-CL brought

'I brought one dog, but Hanako brought two to school.'

If the silent determiners in the ellipsis analysis of NAA are FQs, then a structure like (10) would become plausible. We have, however, good reason to deny that they are FQs.

Nakanishi (2007) points out that FQs have peculiar semantic characteristics. One of them is that they somehow exclude collective interpretations, while their non-floating counterparts would allow both collective and distributive readings as shown in (22) and (23).

(22) Otokonoko-ga kinoo [san-nin] booto-o tukutta.

Boy-NOM yesterday [three-CL] boat-ACC made

'Three boys built a boat yesterday.' ( $\checkmark$ distributive, ??collective)

(Nakanishi 2007: 58)

(23) [Otokonoko san-nin]-ga kinoo booto-o tukutta.

[Boy three-CL]-NOM yesterday boat-ACC made

'Three boys built a boat yesterday.' ( $\checkmark$ distributive, $\checkmark$ collective)

(Nakanishi 2007: 58)

Now observe that a BNP permits both collective and distributive readings:

(24) Otokonoko -ga kinoo yon-dai-no booto-o tukutta.

Boy -NOM yesterday four-CL-no boat-ACC made

'A/The/Some boy(s) made four boats.' ( $\checkmark$ distributive, $\checkmark$ collective)

Since a noun in Japanese is number-neutral, any use of (24) might be concerned with more than one boy. A use of (24) seems true when the boys in question made the four boats together. Such a collective reading is not permitted in (22) that contains a FQ. Thus, the silent determiner that is possibly present in (24) is not a FQ. The silent determiners required for the silent-head approach do not provide the right environment for ellipsis to be well-formed. Therefore, we have no evidence for the entertained possibility of NP-deletion in a structure like (10).

\subsection{Pronominal analysis of null argument anaphora}

I have argued that the silent-head approach has difficulties in explaining the interpretive independence of NAA if we take NAA to be elliptical. NAA might be, however, 
Interpreting Bare Nouns

a sort of pronoun and have nothing to do with ellipsis. The proponents of the silenthead approach could argue that NAA is not structurally related to its antecedent BNP and that NAA contextually receives a variety of interpretations as free variables, just as unbound overt pronouns receive a variety of interpretations. If that is the right analysis of NAA, then one might think that the interpretive independence would not threaten the silent-head approach.

Let's then discuss the details of such a suggestion. Now suppose that unpronounced pronouns constitute NAA. How could the silent-head approach explain the interpretive independence of NAA?

Kind-referential readings of NAA we saw earlier as in (8) can be accounted for by assuming that Japanese contains a small pro, to which a variable assignment assigns an abstract kind as its value. I will argue, however, that existential readings available to NAA as in (6) and (7) cannot be explained in terms of silent pronouns.

In what way could a silent pronoun yield an existential quantification? One possibility is to treat it as a type-neutral variable that can receive a property as its value and to stipulate that the property gets existentially closed. This suggestion, however, defeats the purpose of the silent-head approach because existential closure must be introduced as an independent type-shifting procedure that has no lexical realization. Otherwise, we would have to introduce a silent determiner that takes a pro as its complement and creates an existential quantification, which is exactly the structure that I have refuted in the previous section.

Another possibility is to introduce a silent pronoun that is in itself existential: a context-sensitive existentially quantified NP. For example, we can think of something like the following:

$$
\llbracket p r_{\exists} \rrbracket=\lambda P_{\in D\langle e, t\rangle} \cdot \exists x[\Pi(x) \& P(x)]
$$

(where $\Pi$ is a contextually salient property)

If there is such a pronoun, then we can account for the existential readings of NAA in (6) and (7). ${ }^{1}$

Although the specification of the hypothesized pronoun (25) is logically possible and sufficiently covers the cases at hand, it is empirically deficient because pro $_{\exists}$ overgenerates unattested readings when it interacts with scope-taking devices.

It seems natural to assume that something like pro $_{\exists}$ has multiple scope possibilities. Indeed an overtly existential expression dareka ('someone') interacts with other scope-taking expressions. Consider the following example, in which dareka appears with two other scope-taking expressions:

(26) Sorezoreno sensei-wa [seito no dareka]-ga okorareta Each teacher-TOP student 's someone-NOM scold.PASSIVE.PAST

1 (25) is what Tomioka (2003) discusses as part of a possible analysis of Japanese null arguments. He ultimately objects to (25) and adopts the type-shifting approach to Japanese null arguments. 
to kiita.

COMP heard

Depending on how to interpret seito no dareka ('some student'), (26) has three different readings as follows:

(27) a. For each teacher $x, x$ heard that, for some student $\mathbf{y}, y$ was scolded. (narrowest scope)

b. For each teacher $x$, for some student $\mathbf{y}, x$ heard of $y$ that $y$ was scolded. (intermediate scope)

c. For some student $\mathbf{y}$, for each teacher $x, x$ heard of $y$ that $y$ was scolded. (widest scope)

(27a) is a paraphrase of the narrowest scope reading of (26), which seems true when every teacher heard just that there is some scolded student, without knowing who. Under the intermediate reading (27b), (26) seems true when every teacher learned about a different student that the student was scolded. (26) can also be used to express the thought that there is a particular student such that every teacher learned that she was scolded, as paraphrased in $(27 \mathrm{c}) .^{2}$

Now consider the sentence (28b), which is structurally identical to (26) except that it contains NAA $\varnothing$ in the place of the overt existential expression seito no dareka. The NAA in (28b) takes the BNP seito in (28a) as its antecedent.
a. Sorezoreno sensei-wa seito-ga okorareta to
Each teacher-TOP student-NOM scold.PASSIVE.PAST COMP
kiita.
heard
'Each teacher heard that some student was scolded.'
b. Sikasi sorezoreno oya-wa [ $[\varnothing]$ nagurareta to kiita.
But each parent-TOP [ $\varnothing]$ beat.PASSIVE.PAST COMP heard
'But each parent heard that some student was beaten.'

One can observe that it is very difficult to obtain an intermediate reading analogous to (27b) in (28a) and (28b). If the NAA in (28b) were the silent pronoun pro $_{\exists}$, then we could find an intermediate reading in (28b) as easily as in (26). Therefore, it is undesirable, on an empirical ground, to posit something like pro $_{\exists}$.

2 The existential term in question dareka consists of the indeterminate pronoun dare, which can also form a wh-phrase, and the suffix $k a$. I am not suggesting that dareka must be analyzed as a quantificational phrase analogous to (25). As far as it explains the observed scope possibilities, any analysis would be sufficient. Indeed Yatsushiro (2009) analyzes dareka in terms of choice functions. My claim is that pro $_{\exists}$ would also have different scope possibilities whether it is analyzed as a quantificational phrase or choice function. 
Interpreting Bare Nouns

My contention is not that it is impossible for a silent pronoun to have an existential meaning. We know that overt pronouns can have existential meanings as my glosses earlier, (6) and (7), suggest. I also cite some examples from (Carlson 1977) below:

a. May hates raccoons because they stole her sweet corn.

b. My brother thinks that snakes are nasty creatures, but that hasn't stopped me from having them as pets. (Carlson 1977: 25)

English plural pronouns in these contexts must be existentially interpreted, although their antecedents seem to have kind-referential or generic readings. It is plausible to assume that covert pronouns can have existential meanings as well, if such a pronoun exists at all.

What I am claiming is that such covert pronouns alone cannot generate existential interpretations of NAA. The question we have is whether we can strictly follow the silent-head approach and stay away from any purely semantic procedure to account for the interpretive independence of NAA. I have argued that, with respect to Japanese, we cannot directly encode an existential quantification as the lexical meaning of a covert pronoun. I have also earlier argued that we cannot introduce an existential quantification by positing more structure. We have to appeal to an extra-syntactic rule to generate an existential quantification. As we will see in the next section, we can easily account for the existential interpretations of NAA by introducing a type-shifting rule.

\section{Type-shifting approach}

One of the two approaches to BNPs turns out to be problematic when it applies to Japanese NAA. I will show that the other approach fares very differently, whatever syntactic analysis of NAA is on the right track.

\subsection{Ellipsis analysis of null argument anaphora revisited}

Let's again suppose that NAA is analyzed as a kind of ellipsis. On the type-shifting approach, we do not posit any silent structure for BNPs. If any occurrence of NAA is just an unpronounced BNP, then they have the same syntactic and semantic profiles, as the schematic representation (30a-b) suggests. Assuming that a BNP is a determiner-less NP, the following NAA is also a determiner-less NP as in (30b).

$$
\begin{aligned}
& \text { a. ... BNP ... NAA ... } \\
& \text { b.... NP ...NP ... }
\end{aligned}
$$


If we have an adequate type-shifting account for BNPs, then the exact same account applies to NAA with no modification. For example, if a BNP originally denotes a kind and a type-shifting operation introduces some instance of the kind as Chierchia (1998) argues, then we can say that NAA also denotes a kind, and that the same operation applies to NAA to obtain an existential interpretation. A BNP and NAA have a semantic mismatch when a type-shifting rule applies to only one of them. On the type-shifting approach, nothing other than the analysis of BNPs is required for the explanation of the interpretive independence of NAA. ${ }^{3}$

\subsection{Pronominal analysis of null argument anaphora revisited}

Let's next suppose that NAA is analyzed as a kind of silent pronoun. Again assume that BNPs denote kinds as their lexical meanings. Then we can explain the interpretive independence of NAA by assuming that an unbound pro contextually receives its value and that variable assignments may assign kinds to pros. That is, as before, BNPs and NAA denote kinds, and several type-shifting rules are available to them. If we apply a type-shifting rule to one of them, not the other, then we get the interpretive independence of NAA. ${ }^{4}$

\section{Conclusion}

I have argued that the silent-head approach to Japanese BNPs has difficulties in explaining the interpretive independence of NAA. Whatever syntactic analysis we adopt for NAA, the silent-head approach cannot fully account for the various interpretations available to NAA. On the silent-head approach, if NAA is elliptical, then we would have to appeal to a form of NP-deletion that is not permissible in Japanese. If NAA is pronominal, then we would have to introduce an existential pronoun, which overgenerates unattested readings. I have also presented how easily the type-shifting approach can handle the various interpretations of NAA. Therefore, we should conclude that the type-shifting approach is superior to the silent-head approach.

3 The kind-referential analysis in Chierchia (1998) that I mentioned here is just an example, and does not have to be a definite solution to the semantics of BNPs. Any adequate analysis of BNPs would give us the same result for NAA. For example, as Tomioka (2003) suggests, we could also start from a function of type $\langle e, t\rangle$ as the lexical meaning of a noun, and posit several type-shifting rules to derive the observed interpretations. In such a scenario, BNPs and NAA can have different interpretations when two different type-shifting rules apply to them. Regardless of the particular details of a proposed analysis, the type-shifting approach can handle the interpretive independence of NAA.

4 If we follow Tomioka (2003) and consider a BNP to be a predicate of type $\langle e, t\rangle$, then we can assume that pros are type-neutral and variable assignments assign them functions of type $\langle e, t\rangle$ besides individuals (Tomioka 2003: 330). 
Interpreting Bare Nouns

It is not always clear how to investigate the division of labor between syntax and semantics. Although we have seen several well-developed type-shifting analyses of BNPs, it has been far from clear what is wrong with introducing more structure into BNPs, rather than making semantics complex. I have presented an empirical argument against such an approach to BNPs that posits more structure to account for the available meanings.

\section{References}

Abe, Jun. 2009. Identification of null arguments in Japanese. In Hiroto Hoshi (ed.), The Dynamics of the Language Faculty: Perspectives from Linguistics and Cognitive Neuroscience, 135-162. Tokyo: Kuroshio Publishers.

Carlson, Gregory N. 1977. Reference to Kinds in English. Amherst, Massachusetts: Linguistics Department, University of Massachusetts dissertation.

Cheng, Lisa Lai-Shen \& Rind Sybesma. 1999. Bare and not-so-bare nouns and the structure of NP. Linguistic Inquiry 30(4). 509-542.

Chierchia, Gennaro. 1998. Reference to kinds across languages. Natural Language Semantics 6(4). 339-405.

Dayal, Veneeta. 2004. Number marking and (in)definiteness in kind terms. Linguistics and Philosophy 27(3). 393-450.

Hoji, Hajime. 1998. Null objects and sloppy identity in Japanese. Linguistic Inquiry 29(1). 127-152.

Nakanishi, Kimiko. 2007. Formal Properties of Measurement Constructions. Berlin, Germany: Mouton de Gruyter.

Partee, Barbara H. 1986. Noun phrase interpretation and type-shifting principles. In Jeroen Groenendijk, Dick de Jongh \& Martin Stokhof (eds.), Studies in Discourse Representation Theory and the Theory of Generalized Quantifiers, 115-143. Dordrecht: Foris Publications.

Pylkkänen, Liina. 2008. Mismatching meanings in brain and behavior. Language and Linguistics Compass 2(4). 712-738.

Saito, Mamoru, T.-H. Jonah Lin \& Keiko Murasugi. 2008. $\mathrm{N}^{\prime}$-ellipsis and the structure of noun phrases in Chinese and Japanese. Journal of East Asian Linguistics 17. 247-271.

Takahashi, Daiko. 2008. Quantificational null objects and argument ellipsis. Linguistic Inquiry 39. 307-326.

Tomioka, Satoshi. 2003. The semantics of Japanese null pronouns and its crosslinguistic implications. In Kerstin Schwabe \& Susanne Winkler (eds.), The Interfaces: Deriving and Interpreting Omitted Structures, Amsterdam, The Netherlands: John Benjamins Publishing Company. 
Watanabe, Akira. 2006. Functional projections of nominals in Japanese: Syntax of classifiers. Natural Language and Linguistics Theory 24. 241-306.

Yatsushiro, Kazuko. 2009. The distribution of quantificational suffixes in Japanese. Natural Language Semantics 17. 141-173.

\author{
Yu Izumi \\ Department of Philosophy \\ University of Maryland \\ College Park \\ Maryland 20742 USA \\ yuizumi@gmail.com
}

